\title{
Advancing health through research partnerships in Latin America
}

\author{
Jaime Miranda and colleagues argue that partnerships are key to building and sustaining health \\ research capacity in Latin America
}

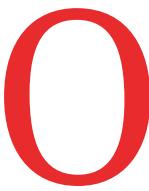

ne of the main objectives of the Pan American Health Organization's (PAHO) policy on research for health ${ }^{1}$ is to develop partnerships to implement appropriate and sustainable health strategies. The policy aims to facilitate the development and scale-up of affordable and accessible products and technologies relevant to the public health challenges of the Americas; develop research groups in PAHO member states with skills that enable the exchange of research knowledge; and facilitate collaboration between diverse stakeholders including the public, government, and the academic and private sectors to tackle national and regional priorities.

Attempts to establish partnerships in the region date back to the 1970s. For example, UNESCO, the United Nations Development Programme, and various other UN agencies funded south-south partnerships among institutions in Latin America-to support research networks in biology, microbiology, and biomedical sciences. ${ }^{2}$ The objective was to promote knowledge exchange and build

\section{KEY MESSAGES}

- Partnerships have been, and will continue to be, crucial for advancing quality health research in Latin America and worldwide.

- PAHO's policy on research for health guides Latin America and provides strong support to promote partnerships.

- Research partnerships in the region should be between equals who share mutually defined objectives and goals.

- For partnerships to be effective, stakeholders need to agree a shared vision and mission; negotiate roles, responsibilities, and actions; define aims; and establish processes for negotiations and sharing power.

- Not all partnerships are identical, and they should evolve based on their unique strengths.

- Latin America will need to adapt to a changing world by sharing information. Data pooling initiatives will challenge existing collaboration paradigms, and a partnership framework can help determine a way forward for the region. research capacity in countries with less well established research infrastructure by training their scientists in larger and more experienced institutions in countries such as Argentina, Brazil, and Mexico. However, many networks broke down because of a lack of national funding. Decades later, some noteworthy examples are emerging of north-south and south-south collaborations and partnerships.

Partnership and collaboration are often used interchangeably, but the relationships are different. ${ }^{3}$ Collaboration entails parties working together in an intellectual endeavour, whereas partnership implies a relationship between equals who share mutually defined objectives and goals. ${ }^{3}$

Developing, implementing, and sustaining partnerships can be challenging and require an understanding of the factors that hinder or promote these partnerships. Cultural barriers and knowledge silos can also affect the pursuit of meaningful partnerships. Here we explore some features of existing research partnerships that are maximising funding opportunities and succeeding in sharing resources, goals, and objectives in Latin America. Case studies were selected to highlight interdisciplinary, interagency, northsouth, south-south, and academia-industry interactions.

\section{Partnerships to produce new knowledge}

The National Heart, Lung, and Blood Institute and the United Health Group have identified a pressing need to build research capacity and infrastructure to tackle the major challenge of the growing non-communicable disease burden in low and middle income countries. ${ }^{4}$ Together, they set up the Chronic Disease Initiative, which ran between 2009 and 2014, to support a network of 11 research centres in 10 low and middle income countries, four of them in Latin America (Mexico, Guatemala, Peru, and Argentina). ${ }^{4}$ Each centre of excellence partnered at least one high income academic institution in the United States, Canada, Australia, or Europe and a local organisation, which could be a university or institution focused on research or healthcare. ${ }^{4}$ Low and middle income countries were the main recipients of grants awarded by the programme, which meant that many had to develop quickly scientifically and bring their administrative and grant management procedures up to international standards. ${ }^{4}$

As of 2016, the four centres of excellence in the Latin America region had engaged in 14 collaborative research projects encompassing various research designs, producing 86 publications and 97 research presentations and training 216 postgraduate researchers. ${ }^{4}$ Additionally, this partnership facilitated a data harmonisation process that enabled further research questions focused on non-communicable diseases to be explored by centres of excellence in the region.

The centres of excellence in Latin America and their global partners mutually benefited from the programme, not only from the scientific advancements but also from the interaction at personal and institutional levels across the continuum, from research conception to disseminating research findings. The centres of excellence for chronic non-communicable diseases achieved success by strengthening research capacity, sharing data and networks, promoting profit and merit pooling, and transforming a single funding effort into a long term venture. Unfortunately, without sustained funding ongoing interactions may suffer, putting the partnership and its research pursuits at risk. This emphasises the importance of supporting networks working in line with current research needs and studying health from a multidisciplinary and multimorbidity perspective instead of working in silos. ${ }^{5}$

\section{Partnerships promoting stakeholder engagement}

Researchers in the region rarely have the opportunity and support from governments to test and recommend public health interventions. Project GUIA (Guide for Useful Interventions for Physical Activity in Brazil and Latin America) is a cross-national multidisciplinary research partnership that has taken a different approach. Rather than evaluating new interventions through a randomised controlled trial and then scaling up those that are successful, the project evaluates public health interventions that are already being implemented in Latin America.

Using an iterative process of evaluation, collating evidence, and adapting interventions, Project GUIA has produced 
academic research evaluations of different public health programmes, leading to federal and national scale-up in Brazil of programmes offering physical activity classes in the community (Academia da Cidade) and programmes encouraging physical activity through provision of public spaces and resources (Academia da Saúde). Similar programmes in other countries, such as Colombia and Chile, are also being evaluated and scaled up. ${ }^{6}$

Project GUIA was funded and coordinated by the Centers for Disease Control and the Prevention Research Centre in Saint Louis, US, in partnership with three universities in Brazil. ${ }^{6}$ The project made use of established public health ties and collaborations between the countries' governments that existed before the project started. A diverse network of partners in academia, government (at all levels), and non-governmental institutions (for example, the PAHO and CELAFISC (Centro de Estudos do Laboratório de Aptidão Física de São Caetano do Sul)) were invited to take part in the project. An important part of its success was the project's approach to cultural sensitivity, which enabled recipient partners to identify or prioritise research efforts according to the local context. ${ }^{6}$

Project GUIA exemplifies the importance of interacting with stakeholders from the outset, strengthening the capacity of researchers and policymakers to use and generate practice based evidence. Disseminating findings for use by regional entities and implementing them within programmes has been recognised as an important aspect of the partnership. ${ }^{6}$

Reflections on the success of Project GUIA have also highlighted the importance of timing. The project began as Brazilian public health agencies were ready to embrace initiatives for non-communicable disease prevention ${ }^{6}$ and at a time when a pool of talented young investigators in Latin America was emerging, ${ }^{7}$ showing that investment in researchers early on in their career can develop into larger initiatives. However, retaining such talent requires further investment. Without such support, it will be a challenge to maintain a flow of talent for working, innovating, and advancing public health efforts to tackle non-communicable diseases in the region. A critical mass of talent is key in using their experience to promote the lessons learnt or sustain knowledge and policy engagement at various levels.

\section{Partnerships for more appropriate and affordable technologies}

Transferring innovations from one region to another does not simply result in desired outcomes, and developing new medical technologies costs time and money. Partnership will therefore be crucial for implementing appropriate and affordable medical technology in Latin America. Partnerships between academia and industry, including north-south and south-south collaboration, could lead to more cost effective, appropriate, affordable, and sustainable interventions for the region's major public health challenges. Moreover, by engaging multiple entities within and between institutions these partnerships can help to build capacity for interdisciplinary research and researchers in Latin America who engage in research and development and innovation.

One example in the region where partnership is being encouraged for global health research innovation is the competitive funding provided by the National Institutes of Health, through its National Cancer Institute. These partnerships are especially relevant given the disease burden in the region: $85 \%$ of cervical cancers worldwide occur in low and middle income countries, with $16 \%$ of cases in the Americas. ${ }^{8}$ One of the current partnerships supported by National Institutes of Health/National Cancer Institute funding includes public and private institutions in Latin America and the US looking at the accessible and affordable use of molecular diagnostics in the early detection of human papillomavirus (HPV) subtypes that can lead to cervical cancer. Specifically, researchers from Latin America and the International Agency for Research on Cancer are working to develop an HPV test based on detecting the activity of oncoprotein E6/E7, which is present in the eight most common HPV subtypes associated with cervical cancer. The study will use pre-existing clinical research networks in Latin America to assess the test's potential as the standard screening tool for cervical cancer. ${ }^{9}$ Another example of a partnership supported by this programme which built on existing networks in Latin America includes the transformation of a non-gas based ablative device, the CryoPen(R) Cryosurgical System, into an inexpensive and portable cryotherapy device that can be operated by any healthcare provider. ${ }^{10}$

The industry, academia, and government partnerships, as described in the policy on Research for Health, rely on setting a joint agenda clarifying responsibilities, strengthening capacity, and sharing data and networks for a long lasting impact on current and emerging public health challenges. However, these partnerships could be at risk if multiple agencies cannot match or align priorities, and changes in political agendas may create obstacles. The development of these partnerships relies on existing and future funding opportunities.
Unless the partners concerned have a sustained product development plan, there is the risk that when the funding ends the interactions facilitated by the partnerships may cease, putting at risk the research and innovation process and, therefore, its targeted products.

\section{Discussion}

Multidisciplinary partnerships promote greater understanding among stakeholders across public and private sectors both nationally and internationally. They are key to tackling current and future health challenges: treating communicable diseases and non-communicable diseases, sustaining public health interventions, and creating innovative solutions for common problems that can be applied in low and middle income countries.

For partnerships to be effective, stakeholders need to agree a shared vision and mission; negotiate roles, responsibilities, and actions; define aims; and establish processes for negotiations and sharing power. ${ }^{11}$ Creating strategic alliances with all potential stakeholders (governments, universities, private sector, funders, international organisations, professional societies, community based organisations, and patient groups) is necessary to tackle national priorities through research for health. Partnerships between different stakeholders are also crucial in achieving the aims of the policy on research for health: improving equity, health, and development. ${ }^{12}$

Nascent research partnerships often fail because of unrealistic budgets and a lack of leadership, negotiation, teamwork, and management skills. Such skills are currently acquired by researchers in Latin America in a learning-by-doing fashion, late on in a professional's career. Introducing and building such skills during undergraduate and postgraduate training could lead to long lasting and sustainable relationships of equals, a prerequisite for meaningful partnerships. Incorporating these skills into the curriculum will require another partnership: one between academic institutions and governments for capacity building.

The Latin America region can take advantage of its diverse population and common languages, mainly Spanish and Portuguese, to build partnerships that would be unlikely to work otherwise. We will have to adapt, as existing challenges (that is, the unfinished agenda of infectious diseases, strengthening health systems, and achieving universal healthcare) will be paired with newer ones, such as multimorbidity, non-communicable diseases, and big data approaches for 
research-issues that will be better dealt with through successful partnerships. ${ }^{13}$ PAHO's policy on research for health provides a basis for involving and aligning multiple agencies dedicated to a common goal: research for health and equity. These alliances and their outputs will be crucial for strengthening health systems dealing with major public health challenges. They will allow benchmarking on health advances, so countries can make evidence informed plans for improving the overall quality of, and access to, health servicesboth being major pillars of the universal health strategy that PAHO and all member states have committed to implement.

We thank Luis Gabriel Cuervo for his ideas and suggestions for this article and Miguel Ossandon for sharing valuable information about the scope of the $\mathrm{NCl}$ Program on Affordable Cancer Technologies for LMIC. We also thank Samantha Brew for help with editing the initial drafts of this manuscript.

Contributors and sources: JJM conceived the ide and structure of this paper and wrote the first draft with assistance from ACCA and LAS. ACCA developed the first literature review, contributed to manuscript writing, and commented on all drafts and revisions. All authors contributed intellectual content, edited the manuscript, and approved the final version. The opinions expressed in this paper are those of the authors and do not necessarily represent those of $\mathrm{PAHO} / \mathrm{WHO}$

Competing interests: We have read and understood BMJ policy on declaration of interests and declare the following interests: JJM has been a member of PAHO's advisory committee on Health Research (ACHR) since September 2014 and chaired the committee from September 2014 to April 2016, served as the PI on the Peruvian Center of Excellence funded by NHLBI. LAS has worked at $\mathrm{NCl} / \mathrm{NIH}$ and $\mathrm{PAHO} / \mathrm{WHO}$.

Provenance and peer review: Commissioned; not externally peer reviewed.
This article is part of a series proposed by $\mathrm{PAHO} / \mathrm{WHO}$ and commissioned by The BMJ, which peer reviewed, edited, and made the decision to publish the article with no involvement from PAHO/WHO. Open access fees for the series are funded by PAHO/WHO.

$J$ Jaime Miranda, research professor ${ }^{1,2}$

Ana Cristina Castro-Ávila, research fellow ${ }^{3,4}$

Luis Alejandro Salicrup, senior adviser for global health research ${ }^{5,6}$

${ }^{1}$ School of Medicine, Universidad Peruana Cayetano Heredia, Avenida Honorio Delgado 430, San Martin de Porres, Lima 31, Peru

${ }^{2}$ CRONICAS Centre of Excellence in Chronic Diseases, Universidad Peruana Cayetano Heredia, Miraflores, Lima 18, Peru

${ }^{3}$ Department of Health Sciences, University of York, York, Yorkshire Y010 5DD, UK

${ }^{4}$ Carrera de Kinesiología, Facultad de Medicina, Universidad del Desarrollo, Clínica Alemana, Santiago 7610658, Chile

${ }^{5}$ Pan American Health Organization/World Health Organization, Washington, DC 20037-2895, USA

${ }^{6}$ Center for Global Health, National Cancer Institute, United States National Institutes of Health, Bethesda, Maryland, USA

Correspondence to: J J Miranda Jaime.Miranda@upch.pe

1 Pan American Health Organization. Policy on research for health (CD49/10). PAHO/WHO, 2009. http://www.paho.org/hq/images/stories/ KBR/Research/research\%20policy\%20on\%20 research\%20for\%20health\%20english.pdf.

2 Sobre RELAB. Red Latinoamericana de Ciencias Biologicas. http://relab.biologia.ucr.ac.cr/?page id=10

3 Glazer G, Alexandre C, Reid Ponte P. Legislative: Partnership or collaboration: words matter. Online Journal of Issues in Nursing 2008;13.https:// www.nursingworld.org/MainMenuCategories/ ANAMarketplace/ANAPeriodicals/OJIN/ TableofContents/vol132008/No2May08/ PartnershiporCollaboration html

4 Engelgau MM, Sampson UK, Rabadan-Diehl C, et al, National Heart, Lung, and Blood InstituteUnited Health Global Health Centers of Excellence
Collaborators. Tackling NCD in LMIC: achievements and lessons learned from the NHLBI-UnitedHealth Global Health Centers of Excellence Program. Glob Heart 2016;11:5-15. doi:10.1016/j. gheart.2015.12.016

5 Academy of Medical Sciences. Addressing the global challenge of multimorbidity: Lessons From BRICS countries. Academy of Medical Sciences, 2017. https://acmedsci.ac.uk/file-download/3855485

6 Parra DC, Hoehner CM, Hallal PC, et al. Scaling up of physical activity interventions in Brazil: how partnerships and research evidence contributed to policy action. Glob Health Promot 2013;20:5-12. doi:10.1177/1757975913502368

7 Pratt M, Brownson RC, Ramos LR, et al. Project GUIA: A model for understanding and promoting physical activity in Brazil and Latin America. J Phys Act Health 2010;7(Suppl 2):S131-4. doi:10.1123/ jpah.7.s2.s131

8 International Agency for Research on Cancer. GLOBOCAN 2012 cervical cancer: Estimated incidence, mortality and prevalence worldwide in 2012. http://globocan.iarc.fr/old/FactSheets/ cancers/cervix-new.asp

9 National Cancer Institute. Supporting the development of affordable technologies for cancer detection, diagnosis, and treatment in LMICs. 2016. https://www.cancer.gov/about-nci/organization/cgh/ blog/2016

10 NIH RePORTER. CryoPen: an innovative treatment for cervical precancer in low-resource setting. $\mathrm{NIH}$ Research Portfolio Online Reporting Tools. https:// projectreporter.nih.gov/project info description. cfm?aid $=9355105 \&$ icde $=37212702$

11 Gallant MH, Beaulieu MC, Carnevale FA. Partnership: an analysis of the concept within the nurseclient relationship. J Adv Nurs 2002;40:149-57. doi:10.1046/j.1365-2648.2002.02357.x

12 Pan American Health Organization/World Health Organization. Milestones for a Policy on Research for Health. 2014.https://www.paho.org/hq/index. php? Itemid $=41201$

13 Sterman JD. Learning from evidence in a complex world. Am I Public Health 2006:96:505-14. doi:10.2105/AJPH.2005.066043

Cite this as: BMJ 2018;362:k2690

http://dx.doi.org/10.1136/bmj.k2690

This is an Open Access article distributed under the terms of the Creative Commons Attribution Non Commercial No Derivs IGO License (CC BY-NC-ND 3.0 IGO), which permits distribution and reproduction for non-commercial purposes in any medium, provided the original work is properly cited. If you remix, transform, or build upon the material, you may not distribute the modified material. See: https://creativecommons. org/licenses/by-nc-nd/3.0/igo/ In any reproduction of this article there should not be any suggestion that PAHO or this article endorse any specific organisation or products 